\title{
Hmong Video: Collective Video Production of Transnational Ethnic Groups
}

\author{
Lin Chen \\ Center for Digital Culture and Media Research \\ University of Electronic Science and Technology of China \\ School of Public Affairs and Administration \\ University of Electronic Science and Technology of China \\ Chengdu, China
}

\begin{abstract}
This paper discusses how the transnational ethnic groups build their cultural identity through collective media production through describing the communication phenomena that Hmong people spontaneously produce Hmong video across border to reflect the pursuit of minority groups of seeking more cultural capital and constructing cultural identity due to the dissatisfaction of with their own status.
\end{abstract}

Keywords-transnational ethnic group; Hmong video; cultural identity

\section{INTRODUCTION}

Zhuang-miao Autonomous Prefecture of Wenshan in the southeast of Yunnan Province borders Guangxi in the east and Vietnam in the south. The Hmong population accounts for $13.68 \%$ of the prefecture's population and Hmong crossborder movement in the area is very active. Inside the Hmong ethnic group, there are Hmong video that tells the story of the traditional culture, the neighborhood relationship, and the family's personal destiny of Hmong in their own language. This Hmong video is widely spread among the Hmong in Yunnan, Guizhou and other places, and is deeply loved by the Hmong. According to local villagers, most of these Hmong videos come from Vietnam, Thailand and other places, and some are also produced by local people. This paper attempts to clarify the emergence and current situation of the Hmong video through the study of transnational communication activities of this transnational group, and expound its significance.

The Hmong call themselves Hmong. It is an international nation originating in China mainly living in South China. In China, the population of Hmong is about 9 million, which is the fourth most populous nation in China. Hmong around the world are originated in China, and thereis also quite large number of Hmong in Southeast Asia. Shi Maoming has defined the concept of "cross-border ethnic groups", "transboundary ethnic groups" and "transnational ethnic group" in the "Research on Transnational Hmong", and believes that "transnational ethnic groups" is more suitable for Hmong because the Hmong is distributed globally. "Trans-nation" has the meaning of "cross-border" and "transboundary". Due to the multinational characteristic of the Hmong, the cross-border activities of Hmong in
Wenshan Prefecture are very frequent, and cross-border communication is also very active.

\section{THE EMERGENCE AND STATUS QUO OF THE HMONG VIDEO}

Under the current communication technology conditions, the marginalized groups have begun their own media production, and the media production of marginalized groups has realized cross-regional and even global collective identity construction through media self-reproduction, such as minority ethnic groups and minority groups.

\section{A. Emergence of the Hmong Video}

According to Foucault's discourse power theory, language is closely related to power, and power comes from language. Language is a field full of oppression and struggle. As a "governing form of language", Chinese deteriorates the production environment of the national language and excludes the national language. The Hmong resists this rejection through the Hmong videos and constructs its own national cultural identity and ethnic identity. This is the most fundamental reason for the emergence and development of Hmong videos.

The breakthrough of technical barriers provided the necessary technical support for the production of the Hmong videos. At that time, the widespread production and popularization of some camera devices such as small DVs and personal cameras lowered the threshold of equipment and the price of equipment got more popular. Some simple and fast editing software is also commonly used in local spontaneous production of Hmong videos. The barriers at the technical level are obviously broken. The minority groups are transformed from the groups that have been represented by others to those who can represent themselves, which can be described as "technical empowerment", giving these groups the power to produce and represent themselves.

The emergence of Hmong videos, the introduction of overseas Hmong videos and the spread of local media also have a great relationship with infrastructure construction. In January 1999, China officially launched the first phase of the village-to-village project through direct broadcasting satellite. 
The local area implemented the "village to village" project in 2002 , when the "village to village" is quite different from the current satellite lid. It can only access to a small number of 4 to 5 stations that are extremely unstable, so the local people lack entertainment life. At that time, the popularity rate of TV was only $40 \%$. Therefore, the Hmong video had a social function. The men, women and children in the village would gather together in some wealthy families with TV to watch the Hmong videos, and even some issues were formed, which led to extensive discussions. This is one of the important reasons for the rise of the Hmong video.

\section{B. The Status Quo of Hmong Videos}

The Hmong mainly consumes images through DVD players. These Hmong videos are sold at local audio distributors at the price of 5-9 yuan. These discs can be roughly classified into multinational images, spontaneous production images, and translated images. Among them, most of discs sold in the market and in the villagers' homes are Hmong videos from overseas countries, followed by translated images. Hmong videos from overseas countries such as "Human Tiger" and "Widow's Tears" are mainly feature films. The discs telling the traditional stories of the Hmong are almost full of mysterious colors. In addition, most of them are feature films telling personal destiny and sorrow. These feature films often evoke a strong resonance of the viewing group. The translated images with largest number are action comedy films and martial arts gods, such as "Fire Burning Red Lotus Temple", "Liu Sanjie" and other movies. The early Hong Kong Kung $\mathrm{Fu}$ movies acted by Hong Jinba, Jackie Chan and so on are very popular. The characteristics of the usually played film are: simple storyline, facial expression (good guy / bad guy) and rich body language. Spontaneously produced Hmong videos are mostly based on the discs of simple singing.

However, the situation has become more and more difficult. The Hmong videos in both domestic and overseas regions still cannot escape the above fixed narrative content and techniques. There is no progress in production with simple shooting and editing, so they are seriously homogenized and shoddy.

\section{THE INTERPRETATION OF THE MEANING OF HMONG VIDEOS}

In modern society, media has become the main field of representation. In the past, ethnic minority groups were often represented by the media. The emergence of Hmong videos is an important way for the Miao group to become the main subject of communication. It realizes the transformation of the Hmong from being represented by other to being represented by them.

\section{A. Construction of Cultural Identity}

Some foreign studies have shown that images play a special role in helping minority groups overcome spatial barriers and maintain ethnic identity, ethnic networks and ethnic traditions. The dominant, iconic culture of the Hmong population is the language. The language of Hmong videos is the reason why the Hmong choose to watch these images. In addition to language, there are many hidden cultural symbols, such as ghost worship, soul worship, the same funeral rituals, and life etiquette, such as baby naming ceremony. When the local villagers watch the film together and see a ceremony, the local villagers say very excitedly: "This kind of ritual is the same as ours. Our traditional culture is well preserved in Vietnam. Now only a few people here can do this." A very special feature of the Hmong is ethnicity. Whether it is the Hmong videos produced by the overseas Hmong people, and then fed back by the domestic Hmong, or the Hmong videos produced domestically, it is a good testimony that they are spread within the Hmong at home and abroad and are only spread within the ethnic group.

\section{B. Meaning and Pleasure}

In the cultural economy, the production of meaning and pleasure is largely based on two ways. One is escape and the other is confrontation. Fiske said: "Escape and confrontation are interrelated and they are indispensable to each other." In the Hmong video, in fact, escape and confrontation exist at the same time, and the pleasure and meaning also exist at the same time. There is no contradiction. They are Hmong, so they like to watch the things of their own nation", "I can hardly understand Chinese TV program, but I am more accustomed to my own language." (They all can speak Chinese) "I like to watch the singing in the Hmong dish because I can also sing folk songs. I like to listen to the songs in the Hmong dish", "I feel happy to watch the Hmong disc", "I want to know the history of the Hmong", and "like watching" are several main reasons why Hmong like this kind of Hmong video. These reasons include both pleasure and meaning. The Hmong people's pleasure in watching the movie is the primary factor that attracts them to watch. This pleasure is actually the exploration and interpretation of a new meaning for this nation as well as the resistance of marginal culture to dominant culture because minority cultures and minority languages are not paid attention by mass media. At the same time, in this process, meaning is also constructed and produced. The structuralism view in cultural studies argues that culture is not an objective experience of a social group, but an area of production significance and experience. Through it, social reality is constructed, produced, and interpreted.

\section{Accumulation of Cultural Capital}

"Cultural capital" is a sociological concept proposed by Bourdieu after expanding the concept of capital in Marxist economics. The accumulation of cultural capital is usually carried out in a way of reproducing. The mainstream news media generally presents ideological closedness, and rarely opens up expression space for vulnerable groups. Due to the continuous suppression of the expression of disadvantaged groups and negative information of these groups, the performance of the news media often hinders the realization of the interests of the disadvantaged groups and their cultural recognition and acknowledgement in the mainstream society.

The transmission of Hmong videos is mainly interpersonal communication and group communication. 
Watching DVDs and even gathering together to watch in the early days forms a public field in which the national culture can be spread to achieve the purpose of cultural capital accumulation. Cultural capital is vital to the development of the nation. The "structuralization" of marginal groups is precisely caused by the lack of cultural capital and the weak position of cultural rights. The lack of cultural capital makes it difficult for the Hmong group to consume or enjoy their own national culture, so they can only accept the more mainstream cultural resources spread by the mainstream media. The Hmong video actually plays a role of the accumulation of cultural capital. Overseas and domestic Hmong hope that these Hmong video can reawaken the vitality of their national culture, accumulate cultural capital, and promote national development to achieve the purpose of having more cultural rights and being able to speak.

\section{THE DECLINE OF HMONG VIDEOS - THE}

\section{DETERIORATION OF CULTURAL PRODUCTION ENVIRONMENT}

As a minority nationality, the Hmong is in the border areas, so it has always been a marginal group and a weak side in cultural power. This has resulted in the lack of channels and resources for representing their culture, and they can only represent themselves through the mass media. For example, when ti comes to the Hmong, most people's impression is the ethnic minority wearing silver on TV, the brutality of the Hmong, the witchcraft of the witchcraft, etc., but these representation are incomplete, and even biased. The Hmong video circulating in the Hmong community is a kind of struggle for the cultural rights of the Hmong group, or a resistance to the mass media's representation of this group. However, whether the Hmong video is produced crossborder or spontaneously in China, the production environment is further aggravated by the "three big mountains" - TV, network and new media.

\section{A. "Three Great Mountains": TV, Internet, and New Media}

The historical moment in which media production and consumption are separated is the result of mass media or mass culture industry involvement or monopoly media production. TV media has developed rapidly in the vast rural areas. The current local TV coverage rate is $90 \%$. Almost every household has its own satellite receiving "pot lid". Through this lid, at least 50 channels can be received, which has greatly enriched the villagers' spare time. Smartphones are also popular. In the village, almost all young people have a smart phone. "We often watch TVs more, and it is not convenient to connect DVDs after accessing TV." "Children like to watch TV, cartoons, so we can only watch with them". "There are some great Han TV dramas, especially Kongfu films of Jackie Chan." "Now, in addition to using TV, almost all people watch TV on mobile phones." The highly educated masses said that "we need to understand the dynamics of the outside world in order to live better, so we pay more attention to news and so on." It can be seen that the impact of $\mathrm{TV}$, internet and new media on Hmong video is enormous.

\section{B. Homogenization Is Serious, and Few New Films and Good Films Have Been Made}

"Now we can't find good discs like before" is the most intuitive expression of the local villagers to current Hmong video. It also reflects the decline of the Hmong video, and the cause for this decline. Serious homogenization and difficulty in producing new films and good films is also an important reason. The content of Hmong video is mainly concentrated in the traditional music of ethnic groups, community public activities, ethnic myths and legends, ethnic festival customs, traditional rituals, ethnic history and modern life, and personal destiny. Discs about personal destiny and ethnic myths account for the largest proportion while the community public activities are paid the least attention to. Most of the discs about personal destiny are tragedies in which the miserable fate of characters in the play is inseparable from the history of the Hmong's migration, defeat, displacement and oppression for thousands of years. It is also because of this historical reason that the unique tragic aesthetic of Hmong people has been formed. The Hmong watching the film often shed tears because of the tragedy of the characters in the play. Therefore, this personal misfortune is blended with the history of the nation's suffering.

\section{The Social Function Is Weakened}

In the early days of Hmong video, due to the situation of local media, popularizing rates of TV and DVD were not high, so the villagers could only gather together in some families with TV and DVD to watch the video, which made the Hmong video have a social function in this process. In the process of watching the film, the villagers, due to the common cultural background, are often called by the main body of the film, and sometimes they form a strong resonance. Sometimes, even some issues are formed and widely discussed among the villagers.

Nowadays, popularizing rate of TV has reached $80 \%$ and most families have TVs and DVDs, so they will watch Hmong discs in their own homes even if they want to watch them. Moreover, due to the popularity of satellite TV and smart phones, the Hmong has greatly reduced the times of watching Hmong videos. The grand scenes of gathering together to watch the Hmong video have ceased to exist, and the social functions brought by this have also lost with the decline of the Hmong video.

\section{CONCLUSION}

Hmong video is a kind of media production spontaneously produced by ethnic minority groups, with its own culture as the core, with its own specific content and complete production, circulation and using process; it is different from domestic "indie film" and the "participatory video" produced by the support and promotion of social actors or OGO. The essence of this is that minority groups express their dissatisfaction with the unequal distribution of cultural resources in the weak position of cultural rights. It is a spontaneous resistance to mainstream culture based on the sense of national cultural identity. At the same time, in the 
process, the production and dissemination of video texts reestablished the identity of national culture. The emergence and rise of Hmong video shows that national culture has its own needs for growth and has a certain market.

\section{REFERENCES}

[1] Zhao Yuezhi. Communication and Society: Analysis of Politics, Economy and Culture, Communication University of China press, 2011. (in Chinese)

[2] Manuel Castel. The Power of Identity, social sciences academic press, 2006. (in Chinese)

[3] Paul Hawkins Editor-in-Chief. Principles of Anthropology in Film and Television (Chinese Version 2), tr. Wang Zhusheng, Yunnan University Press, 2007. (in Chinese)

[4] Zhuang Kongshao. General Theory of Anthropology, Shanxi Education Press, 2004. (in Chinese)

[5] Luo Gang, Liu Xiangyu. The Cultural Studies Reader, China social sciences press, 2000. (in Chinese) 